\title{
Pleural effusion due to intraoperative rupture of an infected renal cyst
}

\author{
Handan Gulec, Semih Degerli, Esra Ozayar, Fatma Bercin, and Saziye Sahin \\ Department of Anesthesiology and Reanimation, Kecioren Educational Research Hospital, Ankara, Turkey
}

Pleural effusion can occur after complicated renal cyst operations. Rupture of the cyst into the retroperitoneal space and diffusion of cyst content through diaphragmatic pores is an unusual cause of pleural effusion. Reports about pleural effusion after renal cyst operation are rare in the literature while the diaphragm is intact. Here we report a case of renal cyst operation complicated with intraoperative cyst rupture and ipsilateral pleural effusion postoperatively. The culture of the cyst and the pleural fluid showed the same organism: Klebsiella pneumonia.

A 57-year-old male patient was admitted to the emergency department. His complaints were right flank pain, high fever and poor health. Urosepsis was diagnosed after routine tests and the patient was referred to the urology department. In his history there was right nephrolithotomy due to kidney stones and stenting during angiography due to coronary heart disease.

After tests for diagnosis of multiple kidney stones, pyonephrosis and a renal cyst approximately $13 \mathrm{~cm}$ in size were identified in the non-functional right kidney. Before nephrectomy and cyst excision, a nephrostomy catheter was inserted into the right kidney with intravenous antibiotic therapy for the treatment of pyonephrosis.

After preoxygenation with $100 \%$ oxygen, anesthesia was induced with thiopental $400 \mathrm{mg}$ and rocuronium $50 \mathrm{mg}$ and maintained with sevoflurane $1.5 \%$ in $\mathrm{N}_{2} \mathrm{O}: \mathrm{O}_{2}(50 \%$ : $50 \%)$. Endotracheal intubation was performed with an $8.0 \mathrm{~mm}$ inner diameter (ID) endotracheal tube.

The nephrectomy operation was started under laparoscopy, but later was converted to open surgery because of very adherent tissues. The kidney tissue and the cyst were totally removed, but in the 50th minute of the operation the cyst ruptured due to adhesions. After the rupture, the content of the cyst diffused to the retroperitoneal area, and the surgeon aspirated and irrigated the area many times. The operation continued for 40 minutes after the rupture of the cyst. The duration of anaesthesia was 100 minutes.

Hemodynamic parameters were stable throughout the operation. The patient was extubated at the end of the surgery but nearly 15 minutes after extubation the patient had difficulty in breathing and he was agitated. Blood gas analysis, which was taken 18 minutes after extubation, showed hypoxaemia; $\mathrm{pH}$ : 7.49; $\mathrm{pO}_{2}: 54 \mathrm{mmHg} ; \mathrm{pCO}_{2}: 30 \mathrm{mmHg} ; \mathrm{HCO}_{3}: 23, \mathrm{SpO}_{2}: 88$ (with an $\mathrm{O}_{2}$ mask). The patient was taken to the intensive care unit because of respiratory distress.

The patient was conscious in the ICU. But on auscultation the right lung sounds were decreased and a serious respiratory distress was present. Chest X-ray revealed a pleural effusion (Fig. 1). The patient's respiratory distress decreased after thoracentesis and chest tube insertion. Cultures of the pleural effusion and of cyst fluid taken during the operation were the same: Klebsiella pneumoniae. Imipenem $500 \mathrm{mg}$ qid, linezolid $600 \mathrm{mg}$ bid and metronidazole $500 \mathrm{mg}$ tid were administered.

The diaphragm was intact during surgery and there was no defect on CT. We thought that there was retroperitoneal fluid transition through the diaphragmatic pores during the operation. The patient's general condition improved with antibiotic therapy and drainage of the pleural fluid. The pathology report indicated chronic pyelonephritis. The patient

Corresponding author: Semih Degerli, M.D., Department of Anesthesiology and Reanimation, Kecioren Educational Research Hospital, Sanatoryum C Ardahan S No. 25 Kecioren, Ankara 06380, Turkey. Tel: 905355805133, Fax: 903123569002, E-mail: drsemih@gmail.com (c) This is an open-access article distributed under the terms of the Creative Commons Attribution Non-Commercial License (http:// creativecommons.org/licenses/by-nc/3.0/), which permits unrestricted non-commercial use, distribution, and reproduction in any medium, provided the original work is properly cited. 


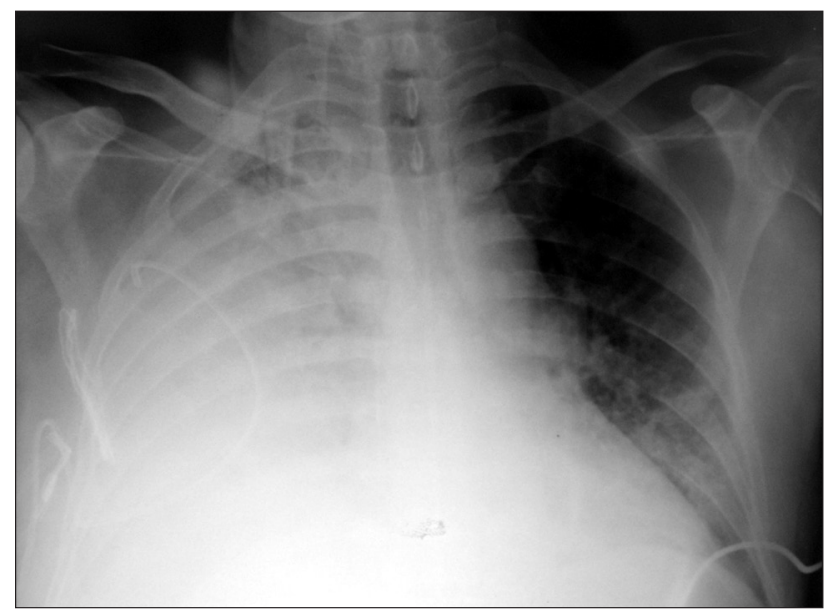

Fig. 1. Pleural effusion was detected on the chest AP X-ray which was taken during respiratory distress.

was referred to the urology department 4 days after surgery, showing improvement in blood gas values, $\left(\mathrm{pH}: 7.35, \mathrm{pO}_{2}\right.$ : $88 \mathrm{mmHg}, \mathrm{pCO}_{2}: 36 \mathrm{mmHg}, \mathrm{HCO}_{3}: 24, \mathrm{SpO}_{2}: 96$ ), respiratory parameters and chest radiography. The chest tube was removed twelve days later and the patient was discharged as healthy.

Pleural effusion may occur for a wide variety of reasons. Commonly, it can be a reactive response to infections, malignancies and heart failure. Pseudochylothorax and urinothorax are uncommon causes of pleural effusion. Also chylothorax is a rare cause of pleural effusion and occurs as a leakage of thoracic duct lymph [1]. Pseudochylothorax is a clinical condition characterized by asymptomatic and usually unilateral pleural effusion. In one case report, bilateral pleural effusion was reported after a percutaneous nephrolithotomy operation [2].

Urinothorax is the other rare cause of pleural effusion; it is detection of the urine in the pleura. Urinothorax occurs when there is diffusion of urine through the pleura due to extravasation of a urinoma and urinary tract obstruction [3]. In our patient, none of the above was the cause of his pleural effusion. The cause was cyst fluid transition through the diaphragmatic pores after rupture of the cyst.

Complications due to infection or renal hydatid cyst rupture have been reported before [4] and there are many cases of intraperitoneal and retroperitoneal renal cyst rupture. But there are only a few reports of cyst rupture causing pleural effusion.

A post-traumatic renal cyst rupture can drain to the peritoneal cavity, retroperitoneum, pelvicalyceal system, and perinephric and subcapsular areas [5]. In our case, the fluid diffused through the diaphragmatic pores during the operation.

In conclusion the anesthesia team should always be careful about pulmonary complications during perioperative periods of renal cyst surgery.

\section{References}

1. Doerr CH, Miller DL, Ryu JH. Chylothorax. Semin Respir Crit Care Med 2001; 22: 617-26.

2. Sharifiaghdas F, Simforoosh N, Ozhand A. A complication after percutaneous nephrolithotomy. Urol J 2010; 7: 199-200.

3. Tortora A, Casciani E, Kharrub Z, Gualdi G. Urinothorax: an unexpected cause of severe dyspnea. Emerg Radiol 2006; 12: 189-91.

4. Kilinç M, Odev K, Güngör S, Karaköse S, Ozeroğlu M, Arslan A. Sonographic diagnosis of the ruptured hydatid cyst of the kidney. Eur Radiol 1997; 7: 392-4.

5. Hughes CR, Stewart PF Jr, Breckenridge JW. Renal cyst rupture following blunt abdominal trauma: case report. J Trauma 1995; 38 : 28-9. 